\title{
Extranodal Lymphoproliferative Processes and Flow Cytometry
}

\author{
Alessandra Stacchini Anna Demurtas Sabrina Aliberti \\ Flow Cytometry Unit, Anatomic Pathology, Diagnostic Laboratory Department, Città della Salute e della Scienza, \\ Turin, Italy
}

\section{Key Words}

Flow cytometry · Fine-needle aspiration cytology · Lymphoproliferative disease · Non-Hodgkin lymphoma . Salivary glands · Thyroid

\begin{abstract}
Objective: Fine-needle aspiration (FNA) cytology is a safe and cost-effective technique for the diagnosis of lymphoproliferative processes, especially when correlated with clinical and imaging studies. However, cytology alone may be unable to detect a lymphoid neoplastic process, as architectural features are less obvious than in histologic preparations and, in certain cases, reactive processes may mimic lymphoma. Flow cytometry (FC) has been recognized as an important ancillary technique in the diagnosis of lymphoid neoplasms and it can be used in conjunction with FNA in the evaluation of lymphoproliferative processes. Study Design: We performed a review of the published literature concerning FC applied to the detection of salivary glands and thyroid lymphoproliferative processes, which are frequently related to autoimmune diseases and difficult to diagnose by cytomorphology alone. Results: $\mathrm{FC}$ is able to detect and subtype non-Hodgkin lymphomas and may contribute to the exclusion of a neoplastic process in cytologically unclear cases. Conclusions: FC can be successfully applied in the differen-
\end{abstract}

tial diagnosis of lymphoproliferative processes in the head and neck region. The FNA-FC combined approach can reduce time to therapy and may prevent unnecessary surgical biopsies.

(c) 2016 S. Karger AG, Basel

\section{Introduction}

Lymphoproliferative processes may be reactive or neoplastic and can affect nodal or extranodal sites. The neoplastic processes involving mature lymphocytes in extranodal sites are mainly non-Hodgkin lymphomas (NHL) of B or T/NK origin; about $30 \%$ of NHL arise from anatomic areas usually lacking lymphocytes [1]. The involvement of tissues other than lymph nodes, spleen or bone marrow may be due to primary or secondary lymphoma [2]. The diagnosis of NHL heavily relies on histologic or cytomorphological examination, supported by immunohistochemistry $[3,4]$. The recognition of disease in extranodal sites may be also challenging for experienced observers due to the morphological overlap between neoplastic and nonneoplastic lymphocytes, or due to the scarcity of tumor cells in the sample. Such difficulty is significant in the evaluation of fine-needle aspiration (FNA) specimens, in which architectural features are 


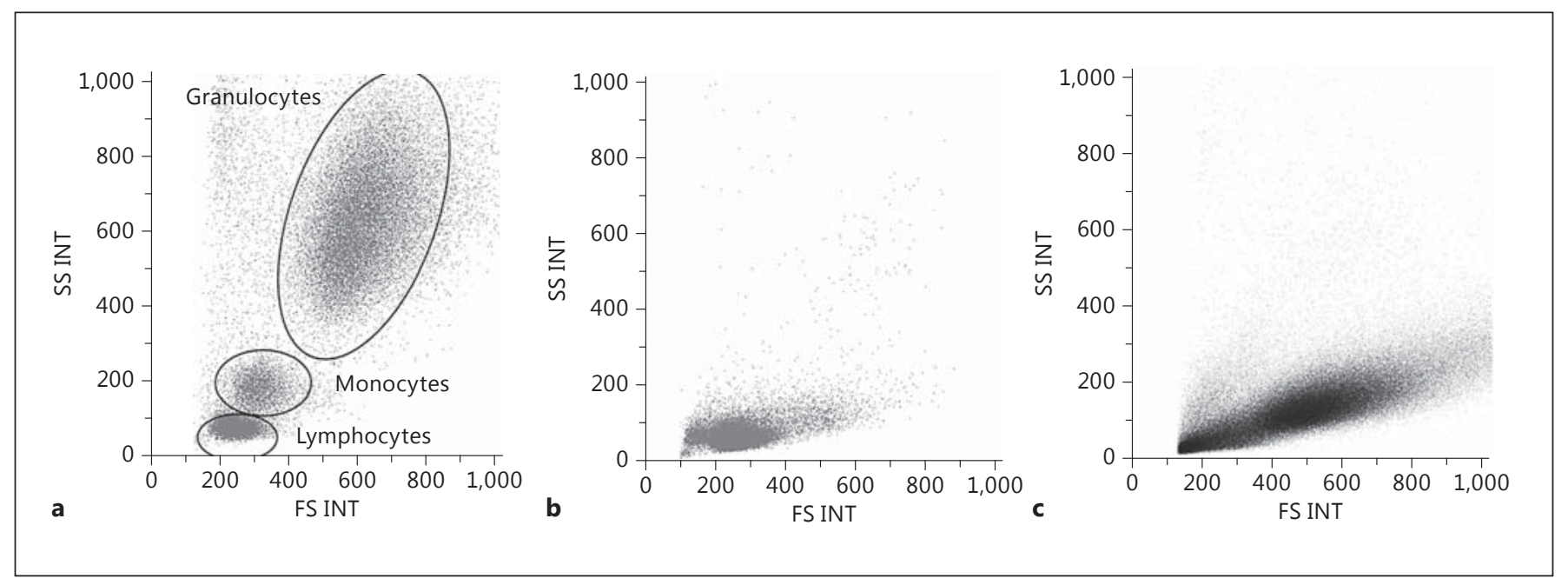

Fig. 1. Examples of FC cell distribution in different samples. a Forward light scatter (FS) versus side light scatter (SS) distribution of the different cell populations in lysed peripheral blood of a healthy patient. b FS versus SS of a fine-needle aspirate taken from a parotid gland in a patient with MALT lymphoma. Mainly small- to

less obvious than in histologic preparations. The World Health Organization (WHO) classification of tumors of hematopoietic and lymphoid tissues, first published in 2001 [5] and updated in 2008 [6], recommends a diagnostic approach which takes into account not only morphocytological characteristics, but also immunophenotypic, genetic and clinical features. Within this framework, flow cytometry (FC) immunophenotyping studies have become an important step in the recognition and characterization of lymphoproliferative processes and lymphomas. These studies are a key tool in the diagnosis and classification of mature B-cell lymphomas, also assisting the diagnosis of mature T-/NK cell lymphoid neoplasms [7]. This overview focuses on the application of FC to detect extranodal lymphoproliferative processes, mainly in the head and neck region, which is the second most common region for extranodal lymphomas and where the differential diagnosis between nonneoplastic lesions and lymphomas may show diagnostic difficulties, especially if performed by cytomorphological examination alone [8].

\section{General Principles of FC}

FC allows the measurement of physical and immunological properties of intact cells in suspension. Fresh samples are incubated with antibody cocktails for antigen recognition; each antibody is conjugated with a different flu- medium-sized lymphocytes are evident. c FS versus SS distribution of lymphocytes in a lymph node taken from a patient with DLBCL. Two different populations are clearly evident: large cells are neoplastic B cells and small cells are mainly T-lymphocytes.

orescent dye (fluorochrome) that allows identification. After the removal of nonbound antibodies and lysis of erythrocytes, samples are acquired on a flow cytometer. The instrument collects signals generated by the disruption of the path of different laser beams (the number of lasers depends on the instrument); the tool also collects fluorescence signals produced by the excitation of the fluorochromes when hit by the light of a laser. Scattering of the light is proportional to cell size in the forward direction (forward light scatter, FS or FSC) and related to cytoplasm complexity (granules, nuclear shape, vacuoles) in the side direction (side light scatter, SS or SSC; fig. 1). Signals are collected by the electronic circuit of the instrument and graphically transformed for further analysis [9].

\section{FC Specimen Source}

Samples used for FC investigation include 'naturally' liquid tissues, such as peripheral blood, body cavity fluids, ocular fluid, and cerebrospinal fluid. Samples taken by aspiration, like bone marrow aspirates or fine-needle aspirates (taken by ultrasound or endoscopic ultrasound techniques) may be processed after the filtration of small cell aggregates, if any exist $[10,11]$. Solid tissues such as lymph nodes, spleen, and tumoral masses can be evaluated after manual or mechanical tissue disaggregation 


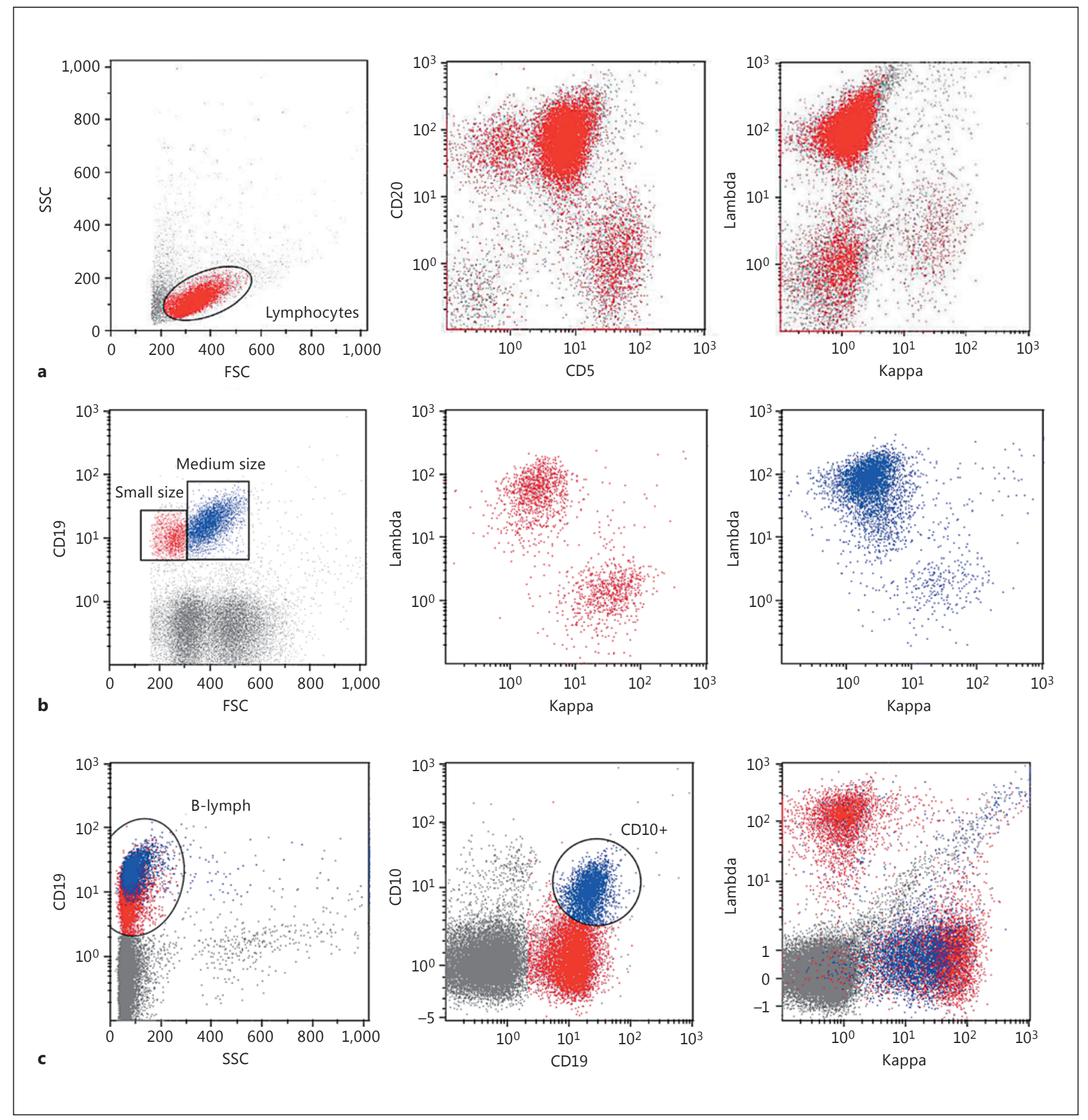

Fig. 2. Examples of FC gating strategies applied to FNA in different lymphomas. a FSC versus SSC analysis gate. Gating on lymphocytes was sufficient to identify the neoplastic $\mathrm{CD} 5^{+} \mathrm{CD} 20^{+} \mathrm{B}$-cell population with monotypical bright expression of the lambda light chain in a mantle cell lymphoma case detected in a salivary gland. b Fluorescence versus FSC analysis gate. Gating on the slightly larger CD $19^{+} \mathrm{B}$ cells (in blue) enabled the isolation of neoplastic B cells displaying a lambda light chain in a case of MALT lymphoma of the thyroid (polyclonal B cells are in red). c Fluorescence versus fluorescence analysis gate. Gating on $\mathrm{CD} 10^{+} \mathrm{CD} 19^{+} \mathrm{B}$ cells (in blue) was required to demonstrate the presence of a monotypical expression of kappa light chain of the neoplastic B cell population hidden among polyclonal B cells (in red) in a case of FL detected in the parotid gland. 
[12]. The use of fluids and aspirates may entail a very limited number of cells and only a single tube to run FC investigations. In these cases, tailored antibody panels should be designed on the basis of clinical features, patient history and specimen source [13].

\section{FC Analysis and Data Interpretation}

FC analysis is a complex process that must be performed by experienced and trained personnel; technical expertise and extensive knowledge in hematolymphoid neoplasms are also required [14]. The overall analysis should include preanalytical steps involving a proper collection, storage and processing. Data interpretation must take into account the sample source and quality (cell amount, viability, apoptotic or necrotic processes), clinical information and other laboratory analyses performed on the same patient material. Data obtained by FC are analyzed by applying the so-called 'gating' procedures, which allow the selection of one or more populations of interest and the exclusion unwanted cells from further analysis. The electronically performed gating procedure combines light scatter and/or fluorescence parameters, which are common to all tubes, to isolate the cells of interest [15]. Multiple gating strategies can be applied to analyze a sample; the choice of the right gating strategy is a fundamental step for the successful detection of the abnormal or neoplastic population (fig. 2). The demonstration of monotypic light chain restriction in all or part of the cells is the most important clue for the presence of a neoplasm of mature B cells [12]; the absence of light chain expression in mature B cells may also be observed [16]. The detection of T/NK neoplasia mostly relies on the abnormal (absent, reduced or increased) expression of antigens that are normally detected, or on the presence of aberrant antigens $[12,17]$.

\section{Salivary Gland Lymphoproliferative Processes}

Salivary glands may be affected by lymphoid proliferations that can be either reactive or neoplastic. Reactive processes include cystic lymphoid hyperplasia and the lymphoepithelial sialadenitis of Sjögren's syndrome (SS), also known as myoepithelial sialadenitis [18]. Neoplastic proliferations frequently include low-grade B-cell lymphomas, such as mucosa-associated lymphoid tissue (MALT) lymphoma, follicular lymphoma (FL) or highgrade diffuse large B-cell lymphomas (DLBCL) [19]; T- cell lymphomas are occasionally reported [20]. Lymphomas of the salivary glands have been reported to frequently occur in patients with SS and lymphoepithelial lesions [21]; SS patients have a $\sim 44$-fold increased risk of developing a malignant lymphoma [22]. The identification of the nature of salivary gland infiltrates has important implications on patients, both in terms of prognosis and management. In the case of an indefinite diagnosis, a partial parotidectomy may be required for histological purposes; this may cause permanent injury to the facial nerve and unaesthetic scars.

Salivary glands do not contain MALT, but may acquire it as a result of chronic inflammation, which usually has an autoimmune origin, as in the case of SS. In SS, lymphoid proliferation affects glandular structures and destroys the epithelial cell compartment, leaving residual myoepithelial cells. MALT lymphoma is often localized, with slow progression and a long history, and it may develop at sites of chronic inflammation as a response to an infection or an immune process [23]. In FNA smears, lymphomas may be very difficult to recognize as benign and neoplastic lymphoid proliferation may display similar patterns and neoplastic cells may be impossible to detect since specific cytological features are often absent [24]. Extranodal MALT lymphomas are composed of a diffuse and heterogeneous infiltrate that includes centrocyte-like cells, monocytoid B cells, small lymphocytes, scattered immunoblasts and centroblast-like cells; plasma cells may also be present [25]. The cytological heterogeneity of MALT lymphoma and the concomitant presence of inflammation often lead to diagnostic errors [8]. Other low-grade B-cell lymphomas, such as FL or largecell lymphomas (DLBCL), may be less difficult to recognize by cytomorphology in the case of a monotonous distribution of small lymphocytes or in the presence of large cells, but can be equally problematic in the case of an insufficient sample or if neoplastic large B cells are poorly represented.

FC has been occasionally reported in combination with FNA of the parotid and submandibular glands (table 1) [25-33]. In 2014 our group published a study in which FC was successfully applied in the distinction between reactive and lymphomatous processes of the salivary glands [34]. In that study, 61 FNA samples from salivary glands were analyzed by both cytomorphology and FC. FC was able to detect and subtype 36 lymphomas: 35 B-cell lymphomas and $1 \mathrm{~T}$-cell lymphoma. Among the 19 cases of B-cell lymphomas with histological confirmation, the majority were low grade, diagnosed as MALT in 11 cases, FL in 4 cases, DLBCL or mixed FL + DLBCL in 
Table 1. Literature reporting the combination of FNA cytology and FC in the diagnosis of lymphoproliferative processes of the salivary glands

\begin{tabular}{llll}
\hline First author [ref.], year & $\begin{array}{l}\text { Samples evaluated by the } \\
\text { combination FNAC-FC (cases) }\end{array}$ & $\begin{array}{l}\text { Final diagnosis: NHL } \\
\text { (subtype if available) }\end{array}$ & $\begin{array}{l}\text { Final diagnosis: benign } \\
\text { or nondiagnostic }\end{array}$ \\
\hline Cha [26], 1997 & parotid (1) & 1 (MALT) & - \\
Mayall [27], 2000 & parotid (4); salivary gland (1) & 1 (MCL) & 4 \\
Crapanzano [25], 2003 & parotid (3) & 1 (B-cell NHL) & 2 \\
Mayall [28], 2003 & parotid (1) & 1 (MCL) & - \\
Zeppa [29], 2004 & parotid (15) & not specified & not specified \\
Zeppa [30], 2010 & parotid (5) & not specified & not specified \\
Schmid [31], 2011 & salivary gland (4) & not specified & not specified \\
Barrena [32], 2011 & parotid (1) & not specified & - \\
Orita [33], 2012 & parotid (1) & 1 (MAT) & - \\
Stacchini [34], 2014 & parotid (60); salivary gland (1) & 36 (B-cell NHL); 1 (PTCL) & 24 \\
\hline
\end{tabular}

MCL = Mantle cell lymphoma; PTCL = peripheral T-cell lymphoma.

a The same case was reported in two different papers.

2 cases, and were not subtyped in 2 cases. All these cases were detected by FC as having a clonal population with a clearly imbalanced $\kappa / \lambda$ ratio in all or part of the B-lymphocytes. The gating strategies used (which each time combined the most appropriate light scatter or fluorescence parameter, as described above) allowed the detection of very small populations (less than $15 \%$ of the overall lymphocytes) hidden in a reactive background. An example is presented in figure $2 \mathrm{c}$.

In this study, FC proved to be useful in excluding a neoplastic lymphoproliferative process. Interestingly, 2 cases that were considered to be suspected lymphomas by cytomorphology and negative by FC, were actually diagnosed as carcinoma and a reactive process, respectively, on histological evaluation. This confirms the value of FC in cases of unclear cytomorphological findings. A benign condition may be confirmed by FC if there is no evidence of an altered T-cell immunophenotype and polyclonal B cells are detected, and also in the case of B-cell expansion, as is frequently observed in reactive processes. In these cases, FC evaluation of $\mathrm{Bcl} 2$ protein expression may be of great help, as normal germinal center B cells do not express Bcl2, or show an expression level below that of normal T-lymphocytes and mantle B cells (fig. 3), whereas $\mathrm{Bcl} 2$ is usually overexpressed in lymphomas $[10,12,35]$.

FC also proved to be useful in detecting T-cell lymphomas. Salivary gland T-/NK cell lymphomas are extremely rare $[18,36]$. T-/NK cell neoplasia may be difficult to recognize either by histology or cytomorphology, leading to diagnostic errors in $>50 \%$ of cases, especially when neo- plastic cells do not display significant morphological alterations or when they are poorly represented in the specimen [37]. We demonstrated that FC was able to easily detect neoplastic cells in a case in which a small amount of T-lymphocytes displayed an altered immunophenotype [34] (fig. 4).

\section{Thyroid Lymphoproliferative Processes}

As salivary glands, the thyroid gland may be affected by reactive or neoplastic lymphoid proliferations. The thyroid gland does not contain native lymphoid tissue, which can appear in various pathological conditions, particularly in the case of autoimmune diseases such as Hashimoto's thyroiditis (HT) [38]. HT results from chronic antigenic stimulation and often induces the clonal selection of B-lymphocytes and lymphoma development [39]. MALT lymphoma occurs in $0.5 \%$ of cases of HT with a slow evolution, often characterized by an indolent course that cannot be easily differentiated from HT evolution [40]. The diagnostic difficulties related to the cytologic recognition of a thyroid MALT lymphoma are similar to those previously described for the salivary glands, in particular that a MALT lymphoma is a mixture of heterogeneous cells that are difficult to distinguish within an inflammatory background. Lymphomas of the thyroid are rare, accounting for only $1-5 \%$ of all lymphomas, and include a wide spectrum of histologic subtypes [38]. Among the NHLs affecting the thyroid, MALT lym- 


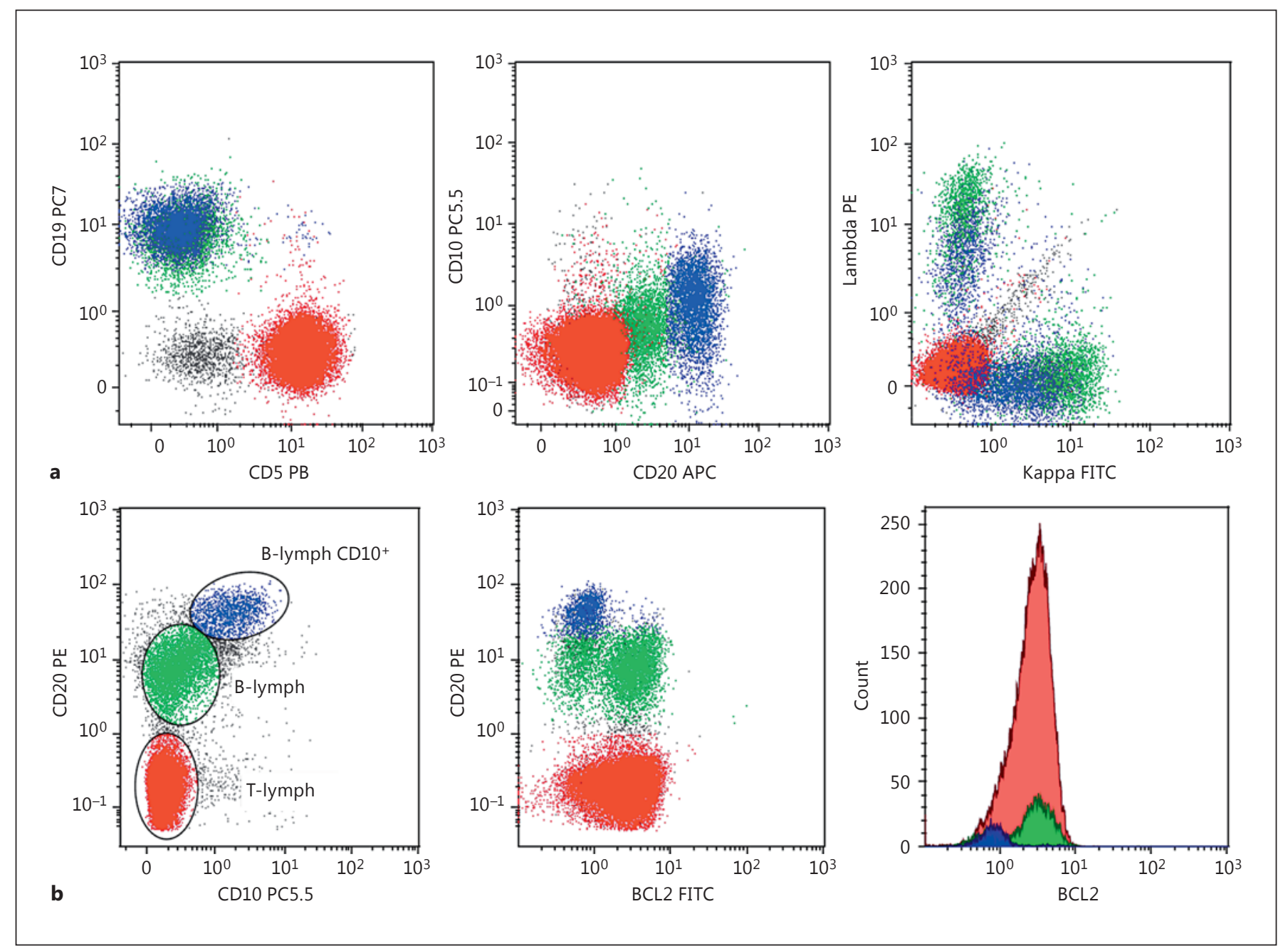

Fig. 3. Examples of FC analysis in an FNA sample of a reactive lymph node. a Gating on all lymphocytes shows the expansion of the $\mathrm{B}$ cell population of the germinal center $\left(\mathrm{CD} 20^{\text {bright }} \mathrm{CD} 10^{\mathrm{dim}}\right)$ depicted in blue; nongerminal center $\mathrm{B}$ cells $\left(\mathrm{CD} 20^{+} \mathrm{CD} 10^{-}\right)$are depicted in green and $\mathrm{T}$ cells are in red. No clonally restricted $\mathrm{B}$ cells were identified either in $\mathrm{CD} 10^{+}$or in $\mathrm{CD} 10^{-} \mathrm{B}$ cells. b $\mathrm{Bcl} 2$ expression levels in the different lymphocyte populations. Nongerminal center $\mathrm{B}$ and $\mathrm{T}$ cells displayed the same $\mathrm{Bcl} 2$ amount; normal germinal center $\mathrm{B}$ cells showed much lower levels of $\mathrm{Bcl} 2$ expression than $\mathrm{T}$ cells and $\mathrm{CD} 10^{-} \mathrm{B}$ cells. phoma accounts for about 25\%, FL for 3-5\%, DLBCL for $70 \%$, and T-lymphomas are extremely rare [40]. The cytological recognition of the different subtypes is closely related to the lymphocyte size (and is easier in a case with monotonous small cells or in the presence of large cells) and to immunohistochemistry results. The combination of FC and FNA produced $97 \%$ sensitivity and $87 \%$ specificity for the detection of B-lymphomas [41]. In a recent paper we demonstrated that the combination of FC and FNA produces a sensitivity and specificity of $100 \%$ in the detection of NHL of the thyroid [42]. Our paper reports the identification of 12 mature B-cell neoplasms (11 B- cell NHL, 1 Burkitt lymphoma, BL) and 1 case of precursor T-lymphoblastic lymphoma (PTLL) among 35 examined samples. The majority of B-cases were MALT type, of which 3 had a previous history of HT. Two of the patients with HT displayed cells with monotypical light chain expression, clearly identifiable by FC among normal polyclonal $\mathrm{B}$ and reactive $\mathrm{T}$ cells (fig. 5). Cytomorphological examination was unable to identify the neoplastic population admixed to lymphocytes of heterogeneous size in these cases. DLBCLs were the second most represented lymphoma subtype in our series. FC was able to identify a very small cluster of clonally restricted CD10- 
Fig. 4. Example of the FC analysis performed in an FNA sample taken from a salivary gland. A T-cell lymphoma was detected by evidencing the presence of a small anomalous T-cell subset (13\% of all lymphocytes, shown in red), which brightly expressed $\mathrm{CD} 5$, and resulted in $\mathrm{CD}^{+}$and $\mathrm{CD}^{-}$at a low intensity. This population was homogeneously positive for CD45RO, displayed a heterogeneous expression of $\mathrm{CD} 2$ and expansion of the $\mathrm{V} \beta 20$ region of the T-cell receptor (TCR).

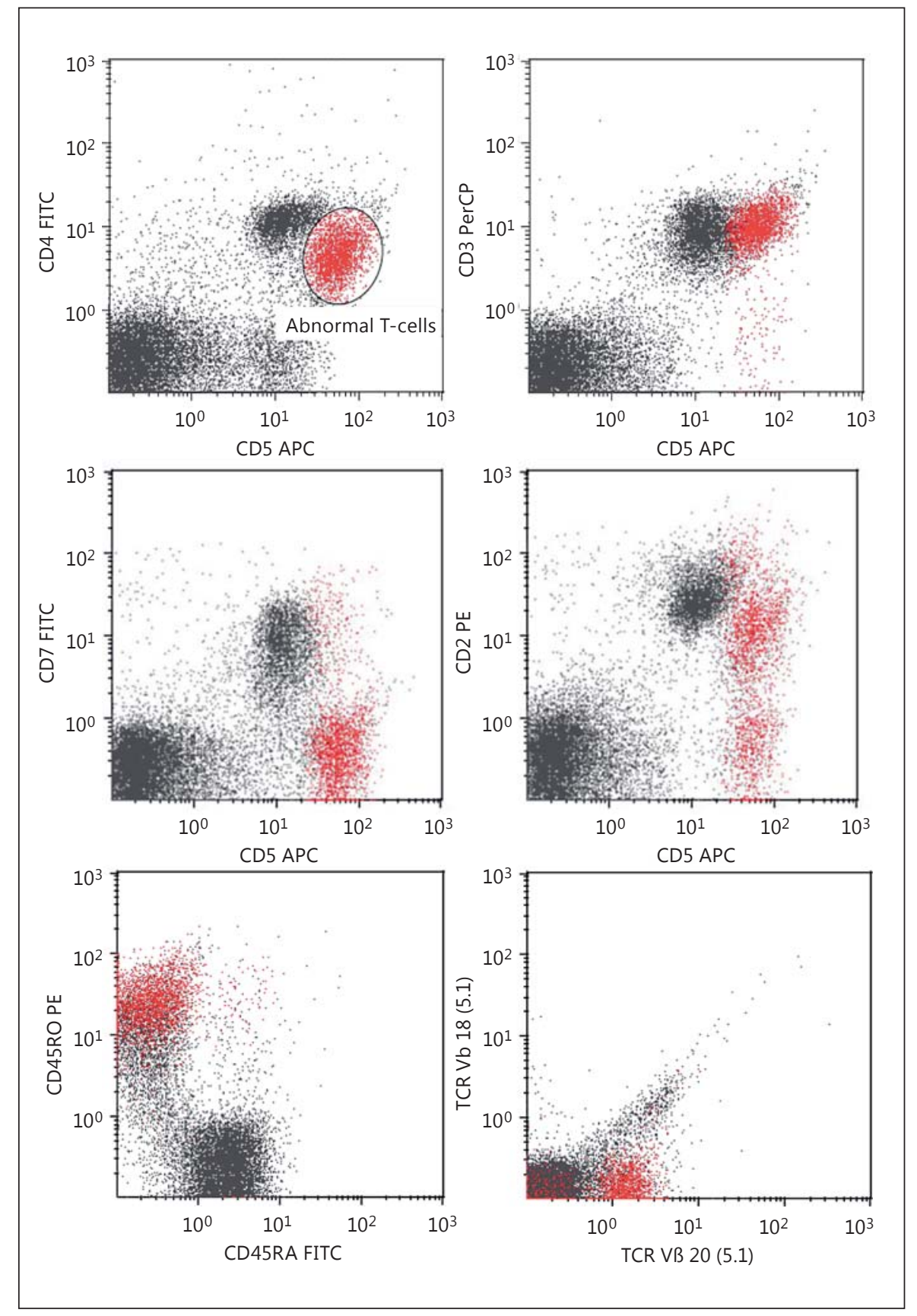

positive large B cells (about 6\% of the total lymphocytes) in a case that was only suspected by cytomorphology (fig. 6). BL, an exceptionally rare form of tumor in the thyroid [43], was suspected in a case where cytomorphology showed monotonous medium-sized lymphoid cells with scant cytoplasm, round nuclei and multiple nucleoli, where FC detected a high number of large B cells with increased CD10 expression. BL was confirmed by the subsequent incisional biopsy and molecular analysis, according to WHO criteria. Cytomorphology suspected the presence of a lymphoblastic lymphoma in a case where monotonous blasts were detected; the patient was finally diagnosed with PTLL by the FC immunophenotyping profile obtained. The short time taken to reach the final diagnosis allowed a prompt start of therapy in $\mathrm{BL}$ and PTLL cases. 
Fig. 5. Example of the FC analysis performed in a case of MALT lymphoma of the thyroid. Gating on brighter CD $19^{+}$cells (in blue) enabled the easy identification of the clonally restricted $\kappa^{+}$population, admixed to normal polyclonal B cells (in red).

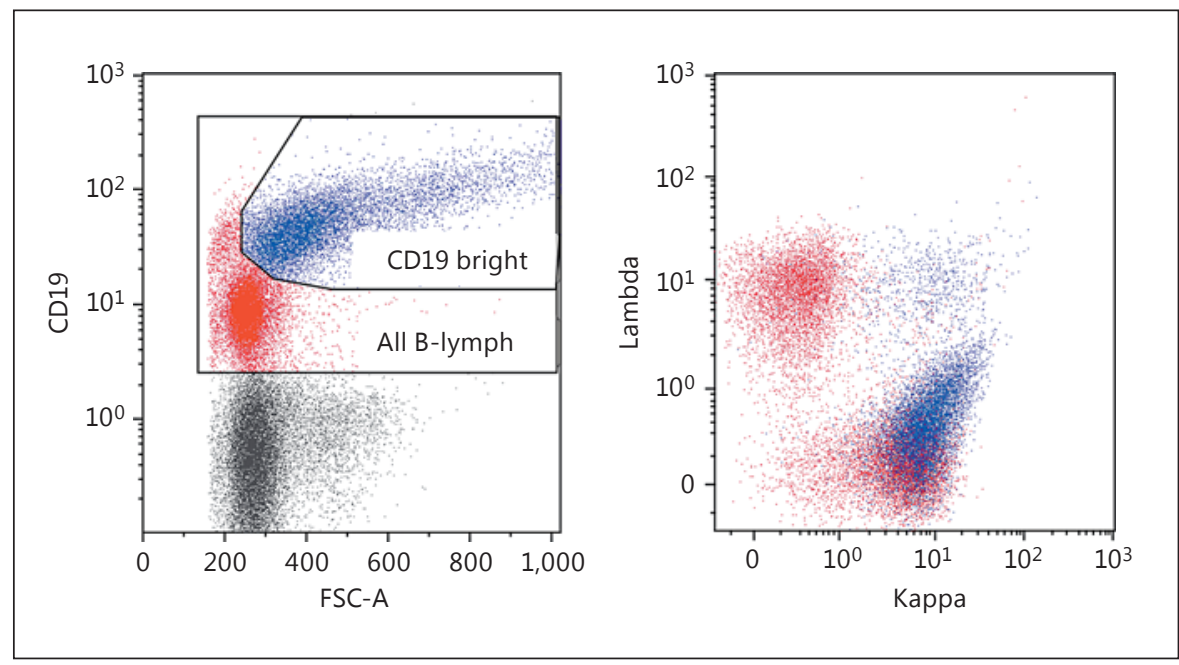

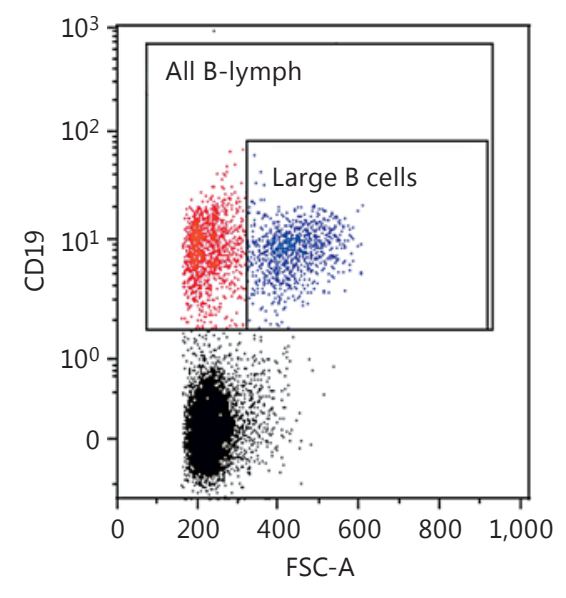
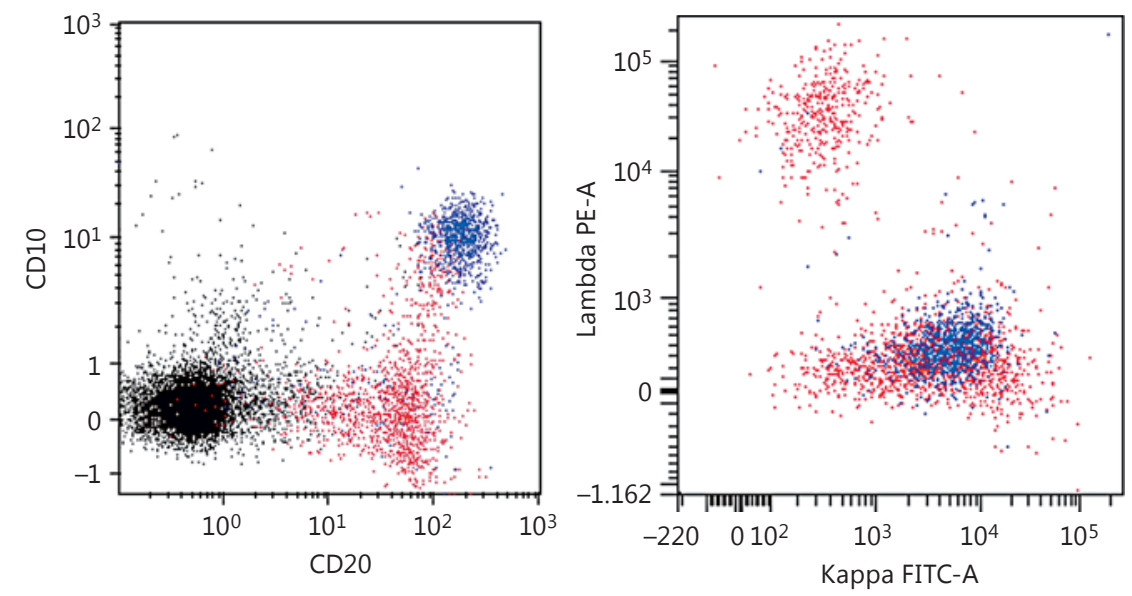

Fig. 6. Example of the FC analysis performed in a case of DLBCL lymphoma of the thyroid. Gating on larger CD19+ cells (in blue) revealed a small cluster of $\mathrm{CD} 20^{\text {bright }} \mathrm{CD} 10^{+}$lymphocytes with monotypic kappa light chain expression.

As previously mentioned, FC may be useful not only in detecting lymphomas, but also in excluding neoplastic lymphoproliferative processes. In this study, FC did not detect any clonally restricted $\mathrm{B}$ cells in 4 patients with a previous history of chronic thyroiditis, all of whom were finally diagnosed as reactive.

Few papers have been published about the combined use of FC and FNA in thyroid lymphomas. The literature that we are aware of that reports the use of FC is listed in table 2 [29-33, 42-58]. Two papers were case reports [48, 54]; some included thyroid specimens in studies per- formed to assess the overall value of FNA in NHL diagnosis $[29,30,32]$. Among the studies carried out to evaluate the role of cytology in the differential diagnosis of thyroid lymphoproliferative processes, only three reports focused on the role played by FC $[42,56,57]$. Our study [42] and the work by Boonyaarunnate et al. [56] reported the highest number of lymphomas identified, both concluding that the combined use of FNA-FC plays a fundamental role in the identification of this rare form of extranodal lymphoma. 
Table 2. Literature reporting the combination of FNA cytology and FC in the diagnosis of lymphoproliferative processes of the thyroid

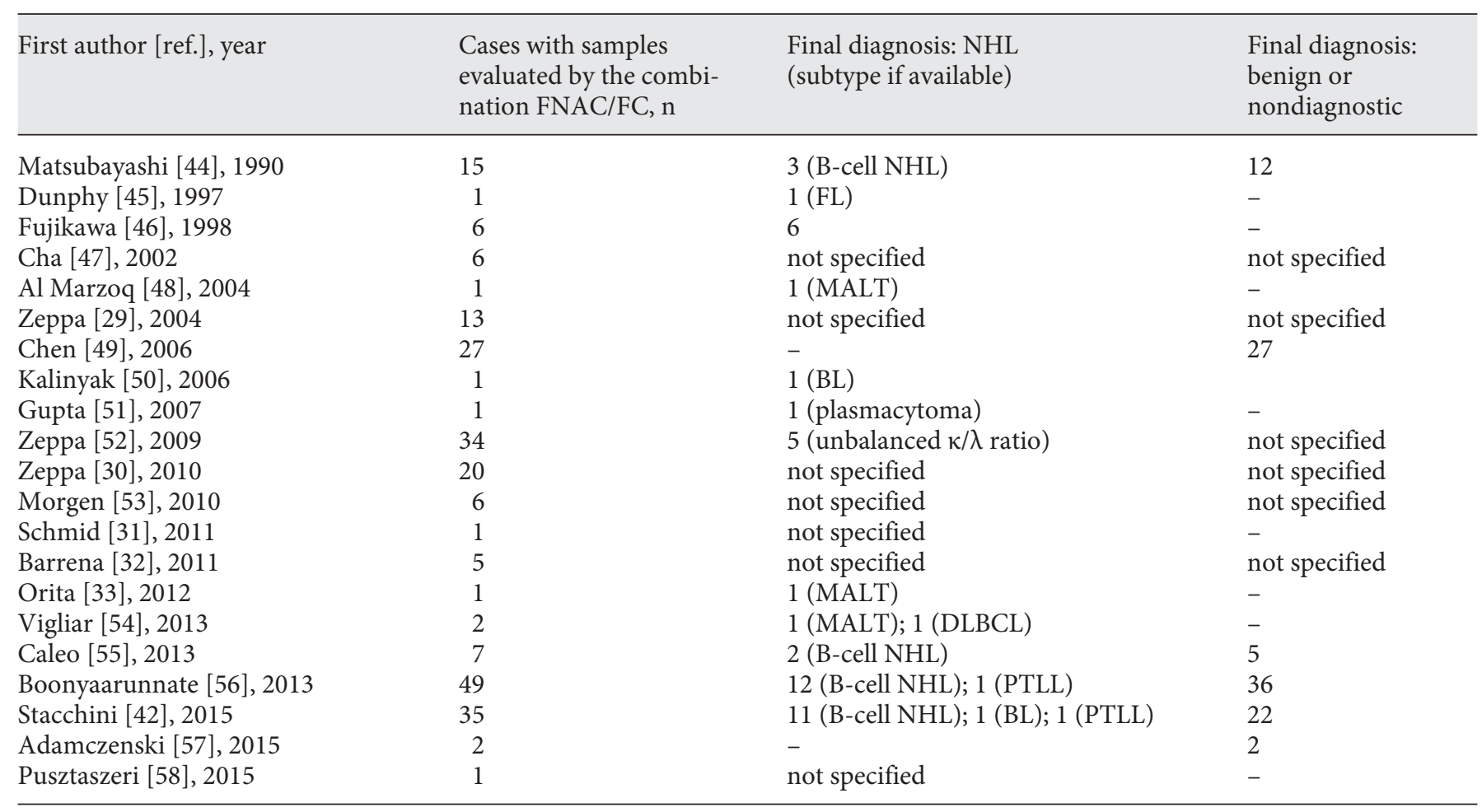

\section{Other Extranodal Lymphoproliferative Processes}

Because of its own flexibility and maneuverability, FNA has been conveniently used in the diagnosis of different pathological processes involving deeply located organs. In the case of lymphoproliferative processes, FC has enhanced the FNA diagnosis by avoiding complex and demanding biopsies. This has been the case with the spleen, in which FNA-FC has been successfully utilized to diagnose and classify primary NHL of the spleen either in their nodular or diffuse clinical presentations [59-62]. In these cases, light chain assessment and cytological atypia are the main clonal criteria for low-grade and high-grade NHL, respectively. Namely, FC enhances the FNA diagnosis when performed by EUS [59, 62]. Whereas breast may rarely be involved by leukemic and lymphoproliferative processes, the occurrence of intranodal lymph nodes and the rare sclerosing lobulitis widens the spectrum of unusual breast lymphoproliferative processes. FNA-FC has been used and described to accurately diagnose these unusual processes, avoiding demanding and useless biopsies, mainly in the case of secondary localizations of myeloid leukemia [63-68]. Whereas the application of FNA to the diagnosis of breast masses is generally declined, these applications still support the utility of its application. In particular, T-cell NHLs, which are rare and difficult to classify, have been accurately diagnosed by FNAFC [67-68]. Mediastinal and pulmonary NHLs have also been conveniently diagnosed by FNA-FC [11, 69-71]. In these anatomical areas, more so than in all the others previously mentioned, rapid on-site evaluation is mandatory for a proper utilization of the diagnostic material and the choice of the most convenient ancillary technique to be utilized.

\section{Conclusions}

The diagnosis of lymphoproliferative processes affecting anatomical sites other than lymph nodes may be challenging by FNA cytology, as architectural features are lost and the morphological overlap between normal and neoplastic cells may be confusing within an inflammatory background. FC is a rapid, reliable and versatile technique for immunophenotyping, able to collect information about cell composition of an FNA specimen, and to correlate the immunophenotype with cell size, detect small atypical populations and obtain a high volume of 
data, also in the case of a sample with few cells. Here, we focused on the role that FC may play as a support to cytology in understanding the nature of lymphoproliferative processes affecting the head and the neck in particu- lar. We believe that FC contributes to the characterization of lymphoid infiltrates, making the association of FNAFC a highly powerful tool in detecting and subtyping NHL in extranodal sites.

\section{References}

1 Rao DS, Daid JW: Small lymphoid proliferations in extranodal locations. Arch Pathol Lab Med 2007;131:383-396.

2 Vannata B, Zucca E: Primary extranodal B-cell lymphoma: current concepts and treatment strategies. Chin Clin Oncol 2015;4:1-17.

-3 Tan LH: A practical approach to the understanding and diagnosis of lymphoma: an assessment of the WHO classification based on immunoarchitecture and immuno-ontogenic principles. Pathology 2009;41:305-326.

4 Jaffe ES, Harris NL, Stein H, Isaacson PG: Classification of lymphoid neoplasms: the microscope as a tool for disease discovery. Blood 2008;11:4384-4399.

5 Jaffe ES, Harris NL, Stein H, Vardiman JW: Tumours of the Haematopoietic and Lymphoid Tissues. World Health Classification of Tumours. Lyon, IARC Press, 2001.

6 Swerdlow SH, Campo E, Harris NL, Jaffe ES, Pileri SA, Stein H, Thiele J, Vardiman JW: WHO Classification of Tumours of Haematopoietic and Lymphoid Tissues, ed 4. Lyon, IARC Press, 2008.

7 Craig FE, Foon KA: Flow cytometric immunophenotyping for haematologic neoplasms. Blood 2008;111:3941-3967.

8 Neskoromna-Jedrejczak A, Tyndorf M, Arkuszewski P, Kobos J: Head and neck lymphomas - diagnostic difficulties. Polsky Przeglad Chirurgiczny 2012;84:113-118.

9 De Tute RM: Flow cytometry and its use in the diagnosis and management of mature lymphoid malignancies. Histopathology 2011;58: 90-105.

10 Demurtas A, Accinelli G, Pacchioni D, Godio L, Novero D, Bussolati G, Palestro G, Papotti M, Stacchini A: Utility of flow cytometry immunophenotyping in fine-needle aspirate cytologic diagnosis of non-Hodgkin lymphoma: a series of 252 cases and review of the literature. Appl Immunohistochem Mol Morphol 2010;18:311-322.

-11 Stacchini A, Carucci P, Pacchioni D Accinelli G, Demurtas A, Aliberti S, Bosco M, Bruno M, Balbo Mussetto A, Rizzetto M, Bussolati G, De Angelis C: Diagnosis of deep-seated lymphomas by endoscopic ultrasound-guided fine needle aspiration combined with flow cytometry. Cytopathology 2012;23:50-56.

12 Demurtas A, Stacchini A, Aliberti S, Chiusa L, Chiarle R, Novero D: Tissue flow cytometry immunophenotyping in the diagnosis and classification of non-Hodgkin's lymphomas: a retrospective evaluation of 1,792 cases. $\mathrm{Cy}$ tometry B Clin Cytom 2013;84:82-95.
13 Stacchini A, Demurtas A, Aliberti S: Immunophenotyping of paucicellular samples. Curr Protoc Cytom 2014;68:9.46.1-14.

14 Johansson U, Bloxham D, Couzens S, Jesson J, Morilla R, Erber W, Macey M: Guidelines on the use of multicolour flow cytometry in the diagnosis of haematological neoplasms. British Committee for Standards in Haematology. Br J Haematol 2014;165:455-488.

15 Calvo KR, McCoy CS, Stetler-Stevenson M: Flow cytometry immunophenotyping of hematolymphoid neoplasia. Methods Mol Biol 2011;699:295-316.

16 Li S, Eshleman JR, Borowitz MJ: Lack of surface immunoglobulin light chain expression by flow cytometric immunophenotyping can help diagnose peripheral B-cell lymphoma. Am J Clin Pathol 2002;118:229-234.

-17 Stacchini A, Demurtas A, Aliberti S, Francia di Celle P, Godio L, Novero D: The usefulness of flow cytometric CD10 detection in the differential diagnosis of peripheral T-cell lymphomas. Am J Clin Pathol 2007;128:854-864.

18 Harris NL: Lymphoid proliferations of the salivary glands. Am J Clin Pathol 1999; 111:S94-S103.

19 Feinstein AJ, Ciarleglio MM, Cong X, Otremba MD, Judson BL: Parotid gland lymphoma: prognostic analysis of 2140 patients. Laryngoscope 2013;123:1199-1203.

20 Yanagawa N, Osakabe M, Furuse H, Maeda K, Tamura G: Peripheral T-cell lymphoma arising from an intraglandular lymph node in the parotid gland: a case report and literature rewiew. Pathol Int 2012;62:60-64.

21 Solans-Laquè R, Lopez-Hernadez A, BoschGil JA, Palacios A, Campillo M, VilardesTarres M: Risk, predictors, and clinical characteristics of lymphoma development in primay Sjögren's syndrome. Semin Arthritis Rheum 2011:41:415-423.

22 Kassan SS, Thomas TL, Moutsopoulos HM, Hoover R, Kimberly RP, Budman DR, Costa J, Decker JL, Chused TM: Increased risk of lymphomas in sicca syndrome. Ann Intern Med 1978;89:888-892.

23 Abbondanzo SL: Extranodal marginal-zone B-cell lymphoma of the salivary gland. Ann Diagn Pathol 2001;5:246-254.

24 Schwock J, Geddie R: Diagnosis of B-cell non Hodgkin lymphomas with small-/intermediate-sized cells in cytopathlogy. Patholog Res Int 2012;2012:164934.

25 Crapanzano JP: Cytologic findings of marginal zone lymphoma. Cancer Cytopathol 2003; 99:301-309.
26 Cha I, Long SR, Ljung BM, Miller TR: Lowgrade lymphoma of mucosa-associated tissue in the parotid gland: a case report of fine-needle aspiration cytology diagnosis using flow cytometric immunophenotyping. Diagn $\mathrm{Cy}-$ topathol 1997; 16:345-349.

-27 Mayall F, Dray M, Stanley D, Harrison B, Allen R: Immunoflow cytometry and cell block immunohistochemistry in the FNA diagnosis of lymphoma: a review of 73 consecutive cases. J Clin Pathol 2000;53:451-457.

28 Mayall F, Darlington A, Harrison B: Fineneedle aspiration cytology in the diagnosis of uncommon types of lymphoma. J Clin Pathol 2003;56:821-825.

29 Zeppa P, Marino G, Troncone G, et al: Fineneedle cytology and flow cytometry immunophenotyping and subclassification of nonHodgkin lymphoma: a critical review of 307 cases with technical suggestions. Cancer 2004; 102:55-65

30 Zeppa P, Vigliar E, Cozzolino I, et al: Fine needle aspiration cytology and flow cytometry immunophenotyping of non-Hodgkin lymphoma: can we do better? Cytopathology 2010;21:300-310.

31 Schmid S, Tinguely M, Cione P, Moch $\mathrm{H}$, Bode B: Flow cytometry as an accurate tool to complement fine needle aspiration cytology in the diagnosis of low grade malignant lymphomas. Cytopathology 2011;22:397-406.

32 Barrena S, Almeida J, Garcia-Macia M, et al: Flow cytometry immunophenotyping of fineneedle aspiration specimens: utility in the diagnosis and classification of non-Hodgkin lymphomas. Histopathology 2011;58:906918.

33 Orita Y, Sato Y, Kondo E, et al: Minimally invasive procedure for accurate diagnosis of mucosa-associated lymphoid tissue lymphoma of head and neck. Jpn J Clin Oncol 2012; 42:325-330.

34 Stacchini A, Aliberti S, Pacchioni D, Demurtas A, Isolato G, Gazzera C, Veltri A, Maletta F, Molinaro L, Novero D: Flow cytometry significantly improves the diagnostic value of fine needle aspiration cytology of lymphoproliferative lesions of salivary glands. Cytopathology 2014;25:231-240.

35 Laane E, Tani E, Björklund E, Elmberger G, Everaus H, Skoog L, Porwit-MacDonald A: Flow cytometric immunophenotyping including Bcl-2 detection on fine needle aspirates in the diagnosis of reactive lymphadenopathy and non-Hodgkin's lymphoma. $\mathrm{Cy}$ tometry B Clin Cytom 2005;64:34-42. 
-36 Yanagawa N, Osakabe M, Furuse H, Maeda K, Tamura G: Peripheral T-cell lymphoma arising from an intraglandular lymph node in the parotid gland: a case report and literature rewiew. Pathol Int 2012;62:60-64.

- 37 Attygalle A, Al-Jehani R, Diss TC, Munson P, Liu H, Du MQ, Isaacson PG, Dogan A: Neoplastic $\mathrm{T}$ cells in angioimmunoblastic T-cell lymphoma express CD10. Blood 2002;99: 627-633.

-38 Thieblemont C, Mayer A, Dumontet C, Barbier Y, Callet-Bauchu E, Felman P, Berger F, Ducottet X, Martin C, Salles G, Orgiazzi J, Coiffier B: Primary thyroid lymphoma is a heterogeneous disease. J Clin Endocrinol Metab 2002;87:105-111.

-39 Aozasa K: Hashimoto's thyroiditis as a risk factor of thyroid lymphoma. Acta Pathol Jpn 1990;40:459-468.

-40 Walsh S, Lowery AJ, Evoy D, McDermott EW, Prichard RS: Thyroid lymphoma: recent advances in diagnosis and optimal management strategies. Oncologist 2013;18:9941003.

-41 Swart GJ, Wright C, Brundyn K, Mansvelt E, $\mathrm{du}$ Plessis M, ten Oever D, Jacobs P: Fine needle aspiration biopsy and flow cytometry in the diagnosis of lymphoma. Transfus Apher Sci 2007;37:71-79.

-42 Stacchini A, Pacchioni D, Demurtas A, Aliberti S, Cassenti A, Isolato G, Gazzera C, Veltri A, Sapino A, Papotti M, Freddi M, Palestini N, Sisto G, Novero D: Utility of flow cytometry as ancillary study to improve the cytologic diagnosis of thyroid lymphomas. Cytometry B Clin Cytom 2015;88:320-329.

-43 Kandil E, Safah H, Noureldine S, Khalek MA, Waddr J, Goswami M, Friedlandel P: Burkittlike lymphoma arising in the thyroid gland. Am J Med Sci 2012;343:103-105.

-44 Matsubayashi S, Tamai H, Morita T, Fukata S, Matsuzuka F, Suzuki T, Kuma K, Nagataki S, Volpé R: Hashimoto’s thyroiditis manifesting monoclonal lymphocytic infiltration. Clin Exp Immunol 1990;79:170-174.

-45 Dunphy CH, Ramos R: Combining fine-needle aspiration and flow cytometric immunophenotyping in evaluation of nodal and extranodal sites for possible lymphoma: a retrospective review. Diagn Cytopathol 1997;16: 200-206.

-46 Fujikawa M, Okamura K, Sato K, Mizokami $\mathrm{T}$, Tanabe S, Ikenoue H, Okamura S, Ohta M, Fujishima M: Usefulness of surface phenotype study of intrathyroidal lymphocytes obtained by fine needle aspiration cytology in autoimmune thyroid disease and malignant lymphoma of the thyroid. Clin Endocrinol (Oxf) 1998;49:191-196.

-47 Cha C, Chen H, Westra WH, Udelsmann R: Primary thyroid lymphoma: can the diagnosis be made solely by fine-needle aspiration? Ann Surg Oncol 2002;9:298-302.
8 Al Marzooq YM, Chopra R, Younnis M, AlMulhim AS, Al-Mommatten M, Al-Omran SH: Thyroid low-grade B-cell lymphoma (MALT-type) with extreme plasmacytic differentiation: report of a case diagnosed by fine-needle aspiration and flow cytometric study. Diagn Cytopathol 2004;31:52-56.

49 Chen HI, Akpolat I, Modr DR, Lopez-Terrada D, De Leon AP, Luo Y, Jorgensen J, Schwartz $M R$, Chang CC: Restricted $\kappa / \lambda$ light chain ratio by flow cytometry in germinal center $\mathrm{B}$ cells in Hashimoto thyroiditis. Am J Clin Pathol 2006;125:42-48.

50 Kalinyak JE, Kong CS, McDougall IR: Burkitt's lymphoma presenting as a rapidly growing thyroid mass. Thyroid 2006; 10: 1053-1057.

51 Gupta R, Naseem S, Kashyap R, Paul L: Role of fine-needle aspirate immunophenotyping by flow cytometry in rapid diagnosis of lymphoproliferative disorders. Diagn Cytopathol 2007;35:381-385.

-52 Zeppa P, Cozzolino I, Peluso AL, Troncone G, Lucariello A, Picardi M, Carella C, Pane F, Vetrani A, Palombini L: Cytologic, flow cytometry, and molecular assessment of lymphoid infiltrate in fine-needle cytology samples of Hashimoto thyroiditis. Cancer Cytopathol 2009;117:174-184.

53 Morgen EK, Geddie W, Boerner S, Bailey D, Gilda da Cunha S: The role of fine-needle aspiration in the diagnosis of thyroid lymphoma: a retrospective study of nine cases and review of published series. J Clin Pathol 2010; 63:129-133.

- 54 Vigliar E, Caleo A, Vitale M, Di Crescenzo V, Garzi A, Zeppa P: Early cytological diagnosis of extranodal stage I, primary thyroid nonHodgkin lymphoma in elderly patients: report of two cases and review of the literature. BMC Surg 2013;13(suppl 2):S49.

55 Caleo A, Vigliar E, Vitale M, Di Crescenzo V, Cinelli M, Carlomagno C, Garzi A, Zeppa P: Cytological diagnosis of thyroid nodules in Hashimoto thyroiditis in elderly patients. BMC Surg 2013;13(suppl 2):S41.

56 Boonyaarunnate T, Olson MT, Ali SZ: Impact of flow cytometry in thyroid cytopathology. Acta Cytol 2013;57:562-566.

57 Adamczewski Z, Stasiołek M, Dedecjus M, Smolewski P, Lewiński A: Flow cytometry in the differential diagnostics of Hashimoto's thyroiditis and MALT lymphoma of the thyroid. Endokrynol Pol 2015;66:73-78.

58 Pusztaszeri M, Wang H, Cibas ES, Powers $\mathrm{CN}$, Bongiovanni M, Ali S, Khurana KK, Michaels PJ, Faquin WC: Fine-needle aspiration biopsy of secondary neoplasms of the thyroid gland: a multi-institutional study of 62 cases. Cancer Cytopathol 2015;123:19-29.

59 Pugh JL, Jhala NC, Eloubeidi MA, Chhieng DC, Eltoum IA, Crowe DR, Varadarajulu S, Jhala DN: Diagnosis of deep-seated lymphoma and leukemia by endoscopic ultrasoundguided fine-needle aspiration biopsy. Am J Clin Pathol 2006;125:703-709.
60 Eloubeidi MA, Varadarajulu S, Eltoum I, Jhala D, Chhieng DC, Jhala NC: Transgastric endoscopic ultrasound-guided fine-needle aspiration biopsy and flow cytometry of suspected lymphoma of the spleen. Endoscopy 2006;38: 617-620.

-61 Zeppa P, Picardi M, Marino G, Troncone G, Fulciniti F, Vetrani A, Rotoli B, Palombini L: Fine-needle aspiration biopsy and flow cytometry immunophenotyping of lymphoid and myeloproliferative disorders of the spleen. Cancer 2003;99:118-127.

-62 Bonifacio A, Goldberg RE, Patterson BJ Haider M: Flow-cytometry-enhanced fineneedle aspiration biopsy of the spleen. Can Assoc Radiol J 2000;51:158-162.

63 Wang P, Yu XM: A primary nipple lymphoma diagnosed by a modified fine-needle aspiration method. Diagn Cytopathol 2012;40:719723.

64 Vigliar E, Cozzolino I, Fernandez LV, Di Pietto L, Riccardi A, Picardi M, Pane F, Vetrani A, Troncone G, Zeppa P: Fine-needle cytology and flow cytometry assessment of reactive and lymphoproliferative processes of the breast. Acta Cytol 2012;56:130-138.

65 Mathiot C, Decaudin D, Klijanienko J, Couturier J, Salomon A, Dumont J, Vielh P: Fineneedle aspiration cytology combined with flow cytometry immunophenotyping is a rapid and accurate approach for the evaluation of suspicious superficial lymphoid lesions. Diagn Cytopathol 2006;34:472-478.

66 Levine PH, Zamuco R, Yee HT: Role of fineneedle aspiration cytology in breast lymphoma. Diagn Cytopathol 2004;30:332-340.

67 Dahmoush L, Hijazi Y, Barnes E, Stetler-Stevenson M, Abati A: Adult T-cellleukemia/ lymphoma: a cytopathologic, immunocytochemical, and flow cytometric study. Cancer 2002;96:110-116.

68 Al Omran S, Mourad WA, Ali MA: Gamma/ delta peripheral T-cell lymphoma of the breast diagnosed by fine-needle aspiration biopsy. Diagn Cytopathol 2002;26:170-173.

69 Marshall CB, Jacob B, Patel S, Sneige N, Jimenez CA, Morice RC, Caraway N: The utility of endobronchial ultrasound-guided transbronchial needle aspiration biopsy in the diagnosis of mediastinal lymphoproliferative disorders. Cancer Cytopathol 2011;119:118126.

70 Zaer FS, Braylan RC, Zander DS, Iturraspe JA, Almasri NM: Multiparametric flow cytometry in the diagnosis and characterization of low-grade pulmonary mucosa-associated lymphoid tissue lymphomas. Mod Pathol 1998;11:525-532.

71 Mehra M, Tamhane A, Eloubeidi MA: EUSguided FNA combined with flow cytometry in the diagnoses of suspected or recurrent intrathoracic or retroperitoneal lymphoma. Gastrointest Endosc 2005;62:508-513.
Flow Cytometry in Extranodal Lymphoproliferative Processes
Acta Cytologica 2016;60:315-325 DOI: $10.1159 / 000448021$ 